\title{
Secure Reconstruction Technique after Partial Nephrectomy Irrespective of Tumor Size and Location
}

\author{
Dong Soo Park, Woong Ki Jang \\ Department of Urology, College of Medicine, Pochon CHA University, Bundang CHA Hospital, \\ Sungnam, Korea
}

\begin{abstract}
Introduction: Nephron-sparing surgery for large renal masses is not considered a safe procedure because of high complication rate. We present our experience using expanded polytetrafluoroethylene $\left(\right.$ Gore-Tex $\left.{ }^{\circledR}\right)$ and Hem-O-Lok ${ }^{\circledR}\left(\right.$ Weck $^{\circledR}$ Clip) as hemostatic agents during open partial nephrectomy (OPN) to perform nephron-sparing surgery for large renal masses.

Materials and Methods: Sixty patients underwent OPN for suspicious renal cell carcinomas. Thirty-four patients with tumors $<2.5 \mathrm{~cm}$ in size underwent OPN with Gore-Tex ${ }^{\circledR}$ alone (group 1). Clinical data from a computerized database were reviewed and compared to a contemporary group of 26 patients with tumors $\geq 2.5 \mathrm{~cm}$ in size who underwent OPN with Gore-Tex ${ }^{\circledR}$ and Hem-O-Lok ${ }^{\circledR}$ (group 2).

Results: The mean patient age was 53 years (range, 35-85 years), and the mean duration of follow-up was 41.8 months (range, 6-56 months). The mean cold ischemic times were 24.0 minutes (range, 12-37 minutes) and 35.3 minutes (range, $18-65$ minutes) respectively in group 1 and 2 . The tumor sizes in groups 1 and 2 were $1.7 \pm 0.4 \mathrm{~cm}$ and $4.74 \pm 2.75 \mathrm{~cm}$, respectively. No major complications, such as urine leakage or delayed bleeding, were noted in either group.

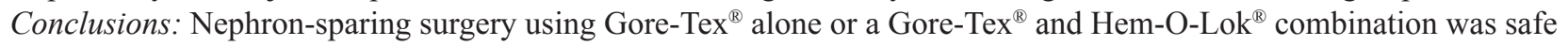
without high-priced hemostatic agents because the tensile strength was sufficient to maintain firmness in the repaired parenchyma. In addition, the procedure is easy to perform and takes less time to complete. Furthermore, major complications, recurrence, and impaired renal function did not occur with this procedure.
\end{abstract}

Key words: carcinoma, renal cell; nephrectomy; partial; surgical technique

Int Braz J Urol. 2009; 35: 416-26

\section{INTRODUCTION}

Since partial nephrectomy was first performed for renal malignancy in 1887 (1), renal cancer surgery has evolved in recent years with a trend toward parenchymal-sparing and minimally invasive approaches. As a result, partial nephrectomy is regarded as a common and appropriate treatment for patients with small renal tumors, even in patients with a normal contralateral kidney. Partial nephrectomy is technically more challenging than radical nephrectomy; therefore, it requires proper techniques. Despite various surgical techniques to prevent postoperative adverse events after nephron sparing surgery, most large series have reported $7.4 \%$ of persistent urine leak, $4.9 \%$ of dialysis, and $2.8 \%$ of acute and delayed bleeding (2). These relatively high complication rates of partial nephrectomy require further special secure techniques to prevent adverse events that should be comfortable to both surgeons and patients. Secure reconstruction technique is particularly needed in high risk patient with large or centrally located tumors. Recently, as 
surgeons have become more comfortable with the technique of partial nephrectomy, renal cancer surgery has advanced during the era of laparoscopy. Moreover, improved renal imaging and the increased detection of small incidental masses have allowed widespread application of laparoscopy in renal cancer surgery. However, laparoscopic partial nephrectomy (LPN) cannot be widely performed due to difficulty in obtaining renal parenchymal hemostasis, and achieving satisfactory caliceal and renal parenchymal repair. In fact, if the defect is too large to be repaired, open partial nephrectomy (OPN) is also difficult to perform due to the excessive tensile force involved, which destroys the remaining renal parenchyma. The power of cinching the suture down on the renal parenchyma is limited in traditional methods of closing the parenchymal defect because of the "cheese slicing" effect of knot tying. To overcome this problem, pioneers have developed several techniques to enhance coaptation strength using exogenous material or clip. Lapra-ty or weck clip are currently used. Clip should be absorbable when it is used to over seal collecting system (3-6). Herein, we present our experience performing a reconstruction technique with OPN, regardless of the size and location of the defect.

\section{MATERIALS AND METHODS}

Retrospective data analysis was performed under the approval of the Institutional Review Board. Between January 2000 and December 2007, 60 patients underwent OPN for suspicious renal cell carcinomas. Two similar, but different techniques were utilized; 34 patients with tumors $<2.5 \mathrm{~cm}$ in size underwent OPN with expanded polytetrafluoroethylene $\left(\right.$ Gore-Tex $\left.{ }^{\circledR}\right)$ alone to bolster closure of the renal parenchyma (group 1), while the other 26 patients with tumors $\geq 2.5 \mathrm{~cm}$ in size underwent OPN with a combination of expanded polytetrafluoroethylene and Hem-O-Lok ${ }^{\circledR}$ (group 2). All procedures were performed by one staff surgeon (DSP). Preoperatively, all patients had spiral computed tomography (CT) and blood sampling for the serum creatinine level. All patients also had repeat blood sampling to obtain a postoperative serum creatinine level at the 1 month follow-up evaluation; spiral CT was performed at the
3 or 4 month follow-up evaluation to identify any delayed complications.

Group 1 - Expanded polytetrafluoroethylene alone. After exposing the renal tumor with the overlying fat and surrounding normal parenchyma, renal artery and/or vein are clamped to reduce bleeding and renal tissue turgor in all cases. It is especially helpful when repairing renal parenchyma after resecting large or embedded tumors. Ice slushing around the kidney is performed in all cases. Then, the renal tumor was resected with a $1 \mathrm{~cm}$ or adequate available margin and the resection margin were confirmed based on frozen section analysis. First, the exposed arcuate arteries and opened collecting system were repaired with 4-0 absorbable suture material. The remaining renal parenchyma was approximated with 2-0 absorbable suture with expanded polytetrafluoroethylene using a vertical mattress suture method. The expanded polytetrafluoroethylene was fashioned into two strips, $1.0 \times 1.0 \mathrm{~cm}$ in size each, and prepared for use. The needle was passed through one piece of the expanded polytetrafluoroethylene and the renal parenchyma in turn. After passing through the opposing renal parenchyma, the needle was passed through the other piece of expanded polytetrafluoroethylene in an outward direction. For the vertical mattress suture method, the needle was passed through the expanded polytetrafluoroethylene again and returned to the opposing side in the same manner. Then, the suture material was tightened, bringing the parenchyma together. Before cinching both sides of the resection margin, oxidized cellulose $\left(\right.$ Surgicel $^{\circledR}$ ) was often used for plugging excessive defects after controlling all bleeding. The procedure was completed after the surgeon released the clamping and verified no further bleeding (Figure-1)

Group 2 - Combination of expanded polytetrafluoroethylene and Hem-O-Lok ${ }^{\circledR}$. - After resection of a large renal tumor, the exposed vessels and opened collecting system were repaired with 4-0 absorbable suture material, followed by suturing of the defective inner medulla portion with 3-0 absorbable suture material. Then, both ends of the resection margin, including the renal cortex and the outer zone of the renal medulla, were approximated with prepared 2-0 absorbable suture materials which were comprised of a strip of expanded polytetrafluoroethylene $(0.9 \times 0.9$ 


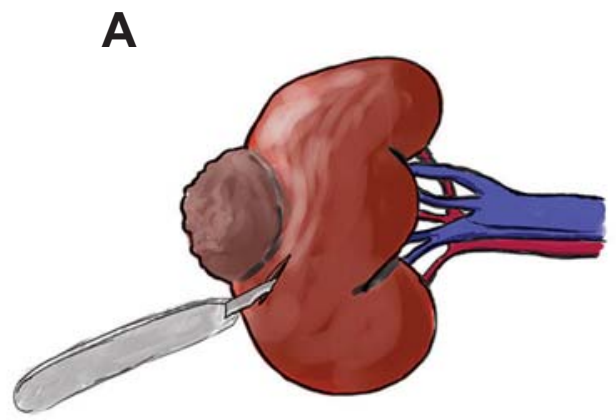

B

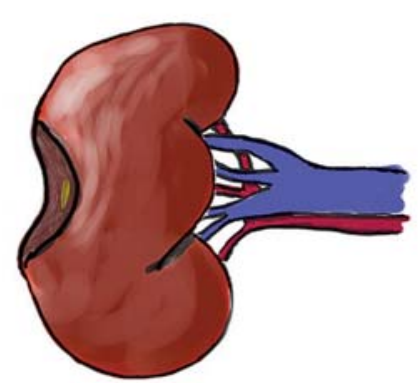

C

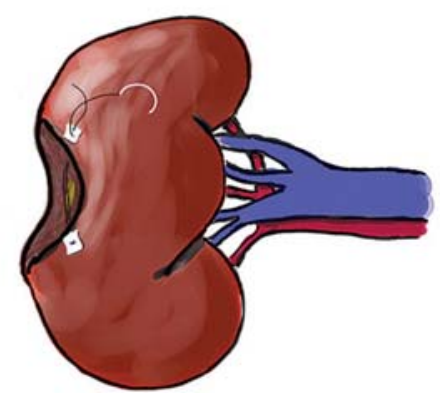

Figure 1 - Mono-material method (Gore-tex ${ }^{(B)}$ only). A) The renal tumor was resected with a $1 \mathrm{~cm}$ margin. B) The exposed collecting system and vessels were repaired. C) Both ends of the resection margin were sutured with prepared 2-0 absorbable suture materials, which were comprised of a strip of expanded polytetrafluoroethylene using the vertical mattress suture method.

cm in size) and a Hem-O-Lok ${ }^{\circledR}$ clipped outside. Knot was made in advance at the distal one third of suture material before suturing to prevent the polytetrafluoroethylene and a Hem-O-Lok ${ }^{\circledR}$ clip from slipping off. The prepared suture material was passed through the renal parenchyma once on each side of the resection margin and another strip of expanded polytetrafluoroethylene and a Hem-O-Lok ${ }^{\circledR}$ was applied. Then, both sides of the resection margin were cinched and the suture material was tied. Oxidized cellulose (Surgi$\mathrm{cel}^{\circledR}$ ) was applied if needed. The procedure was then terminated (Figures 2 and 3 ).

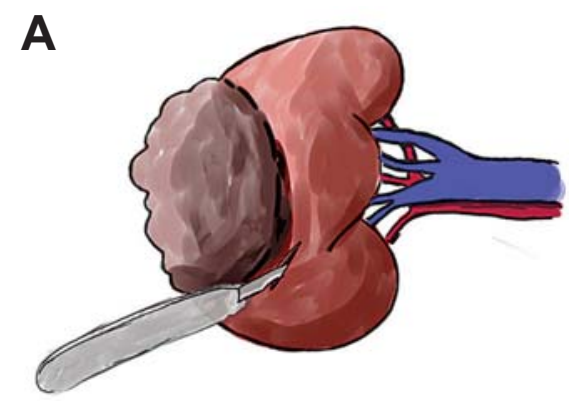

B
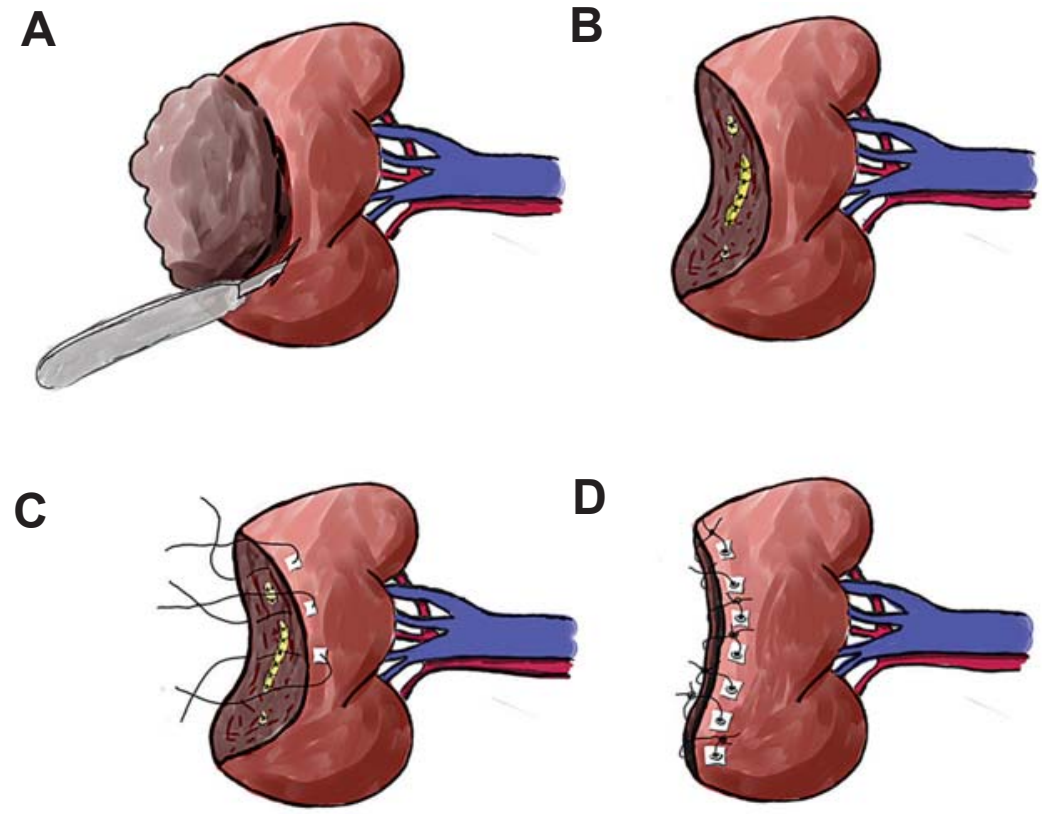

Figure 2 - Combination-material method (Gore-tex ${ }^{\circledR} \&$ Hem-O-Lok $\left.{ }^{\circledR}\right)$. A) The renal tumor was resected with a $1 \mathrm{~cm}$ or adequate available margin. B) The exposed collecting system and vessels were repaired. C) Both ends of the resection margin were sutured with prepared 2-0 absorbable suture materials, which were comprised of a strip of expanded polytetrafluoroethylene. D) Knot was made in advance at distal one third of the suture material. Several Hem-O-Lok ${ }^{\circledR}$ clips were applied just proximally to knots and outside of the strips, preventing suture material from slipping and the renal parenchyma was cinched followed by tying of the suture materials. 


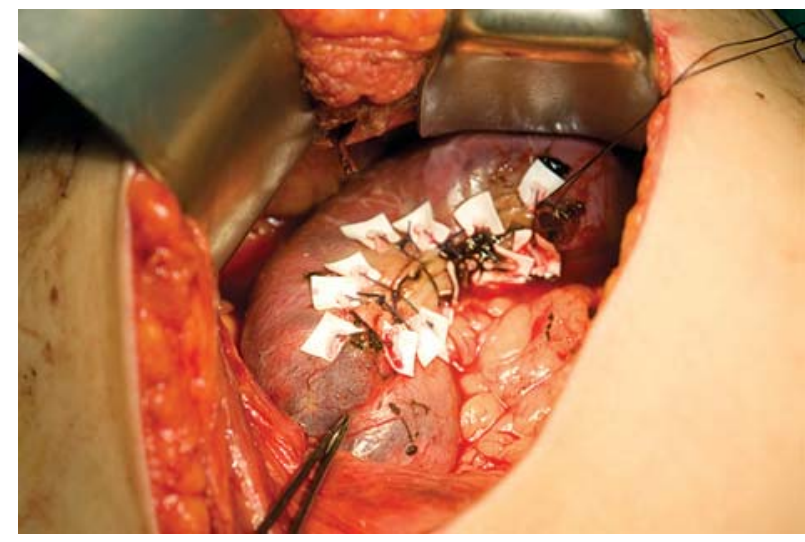

Figure 3-Firm renal parenchyma after the combination-material method.

\section{RESULTS}

The demographic and perioperative data are presented in Table-1. Tumor location at upper, midupper, mid, mid-lower, and lower pole were 17, 5, 26, 4 , and 8 cases respectively. Masses were presented as 17 cases of exophytic shape, 8 cases of intraparenchymal location, and 35 cases of mixed type. There was one case of bilateral angiomyolipoma and none of solitary kidney. Several presenting locations and shapes of tumor on CT imaging taken at pre- and postoperative period are presented in Figure-4. Pathologic stage of renal cell carcinoma cases were 47 of pT1, 2 pT2, 1 of pT3. Eleven cases of Fuhrman's nuclear grade I, thirty-five cases of grade II, three cases of grade III, and one case of grade IV were presented.

In all cases, expanded polytetrafluoroethylene alone or the combination of expanded polytetrafluoroethylene and Hem-O-Lok ${ }^{\circledR}$, were successful in obtaining strict hemostasis of the surgical bed during surgery. Furthermore, no patient had any evidence of acute or delayed bleeding which required blood transfusion. There were no problems with immediate or delayed urine leakage in any of the patients at the 1 month follow-up evaluation. Our reconstruction technique did not require ureteral stent or catheter indwelling in any cases. Moreover, no nephrons were impaired after the nephrectomy in any case. The postoperative pathologic data are presented in Table-2. Two renal cell carcinoma patients from group 2 had metastatic lesions at liver at postoperative follow-up period. One case was a $3.5 \mathrm{~cm}$-sized tumor in a patient with in-

Table 1 - Demographic and perioperative data.

\begin{tabular}{lcc}
\hline Variables & Group 1 & Group 2 \\
\hline N patients & 34 & 26 \\
Mean patient age (range) & $50.5(35-72)$ & $56.62(39-85)$ \\
N gender (\%) & & \\
$\quad$ Male & $23(67.6)$ & $17(65.4)$ \\
$\quad$ Female & $11(32.4)$ & $9(34.6)$ \\
Tumor shape & 10 & 7 \\
$\quad$ Exophytic & 5 & 3 \\
Intraparenchymal & 19 & 16 \\
$\quad$ Mixed & $1.73 \pm 0.44$ & \\
Mean & $1.0 \pm 0.3$ & $4.74 \pm 2.75$ \\
Preop. tumor size (cm) & $1.1 \pm 0.3$ & $0.9 \pm 0.2$ \\
Preop. Cr. level (mg/dL) & $24.0(12-37)$ & $1.1 \pm 0.2$ \\
Postop. 6 months Cr. Level (mg/dL) & $13.5 \pm 1.0$ & $35.3(18-65)$ \\
Cold ischemic time (min) & $12.1 \pm 0.9$ & $13.4 \pm 1.2$ \\
Preop. hemoglobin & & $11.8 \pm 0.8$ \\
$\quad$ Postop. day-1 hemoglobin & & \\
\hline
\end{tabular}


A

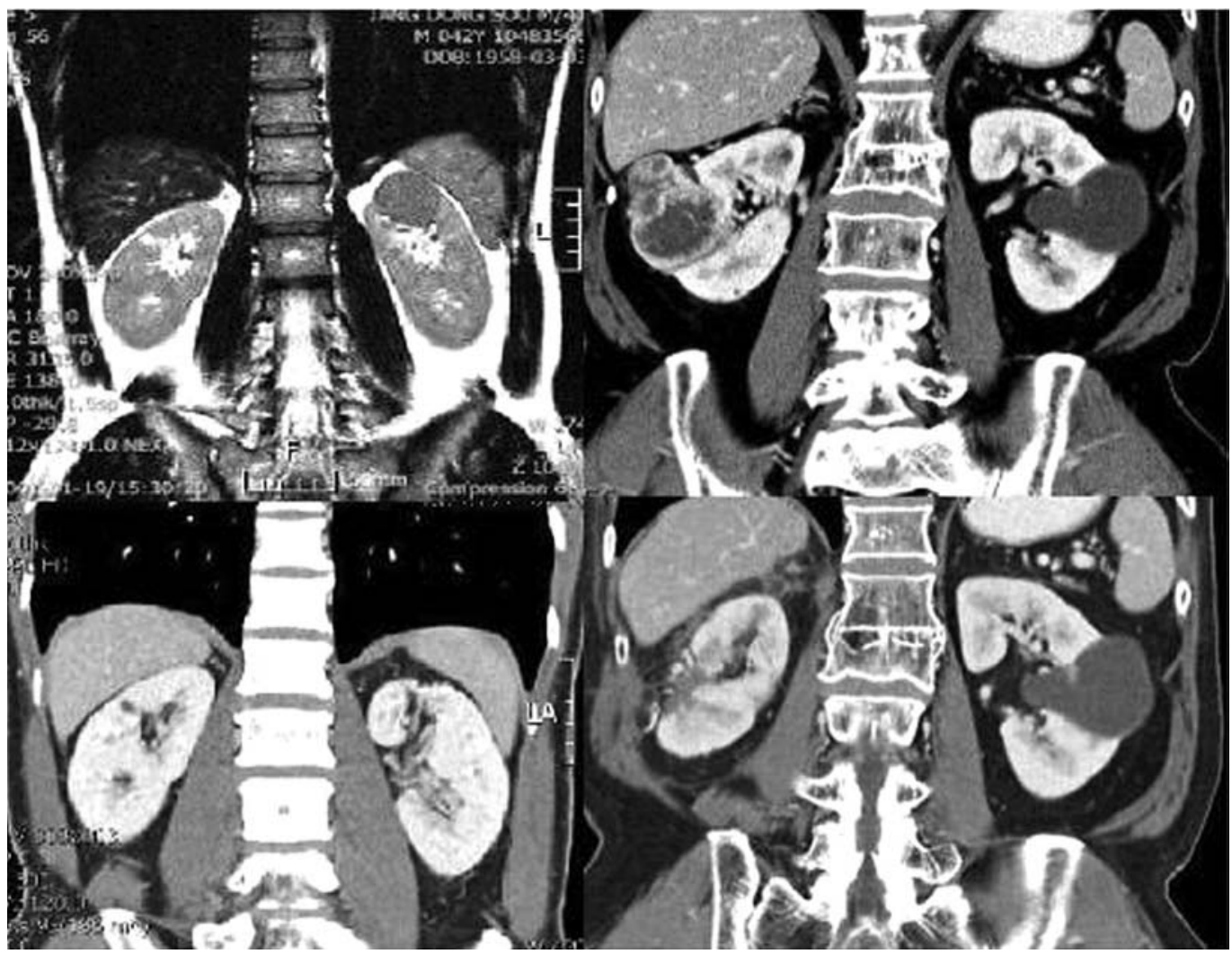

B

C

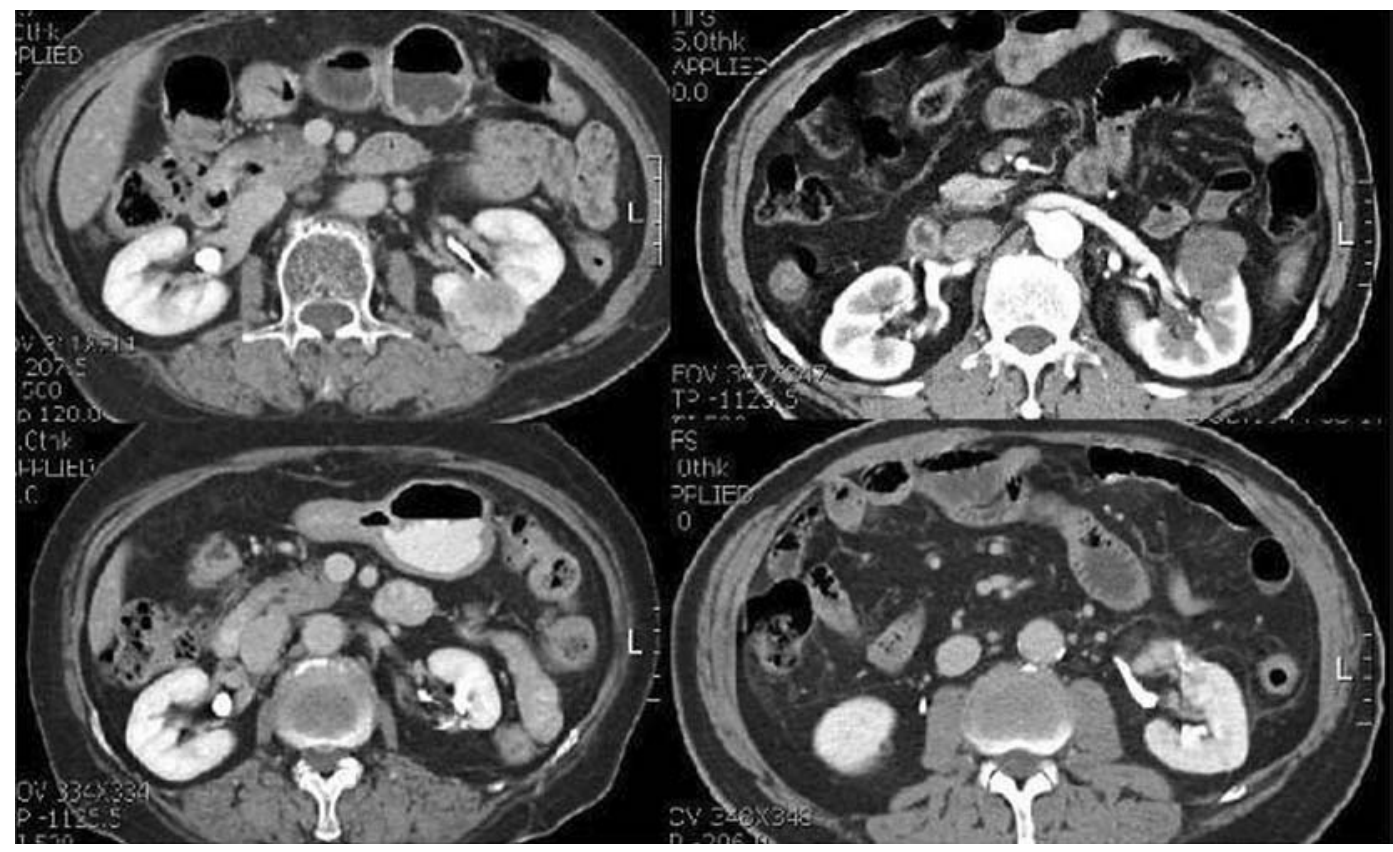

Figure 4 - Preoperative (upper) and postoperative (lower) CT or MR images of various tumor locations and shapes. A) Left renal upper pole mass and intraparechymal type presentation. B) Right renal midportion mass. C) Left renal lower pole mass. D) Left renal hilar mass. 
Table 2 - Postoperative pathologic data.

\begin{tabular}{lcc}
\hline Histological Features & $\begin{array}{c}\text { Group 1 } \\
(\mathrm{N}=34)\end{array}$ & $\begin{array}{c}\text { Group 2 } \\
(\mathrm{N}=26)\end{array}$ \\
\hline Renal cell carcinoma & 29 & 21 \\
Clear cell & 26 & 19 \\
Chromophobe & 1 & 2 \\
Papillary & 2 & 0 \\
Angiomyolipoma & 2 & 3 \\
Others & 3 & 2 \\
\hline
\end{tabular}

traparenchymal type at initial presentation who had a metastatic lesion at 2 years follow-up. Pathology was a conventional clear cell type with Fuhrman's nuclear grade II. Another patient had a pulmonary metastatic renal cell carcinoma with $5 \mathrm{~cm}$-sized primary tumor at initial presentation. Cytoreductive partial nephrectomy was performed and metastatic lesion at liver developed after one year postoperatively. Pathology was a conventional clear cell type with Furman's nuclear grade III.

\section{COMMENTS}

Partial nephrectomy is becoming the standard of care for selected T1a renal cell tumors (7). For renal cell carcinomas $\leq 4 \mathrm{~cm}$ in diameter, the local recurrence rate after partial nephrectomy is $0-3 \%$, with no significant differences in survival rates between patients who have undergone radical nephrectomy $(7,8)$. With the increasing focus on minimally invasive surgery, advanced ablative and complex reconstructive procedures are being performed laparoscopically. Therefore, LPN has emerged as an attractive treatment modality for select patients with small renal tumors. By duplicating established surgical principles, recent techniques of LPN combine the advantages of minimally invasive surgery and the time-tested oncologic and reconstructive efficacy of OPN (9-12). However, the two most significant challenges facing the urologic surgeon during LPN include bleeding control and collecting system repair. When the indications for partial nephrectomy are expanded, e.g., in patients with multiple tumors, more centrally located tumors or tumors $>$
$4 \mathrm{~cm}$ in size, the risk of the specific, technically-related complications increase. In open surgery, various techniques have been used to assist with hemostasis of the transected renal surface, including temporary vascular occlusion, vessel suture ligation, renal compression, and special surgical equipment. However, it is these challenges of hemostasis and collecting system closure that have limited the application of nephron-sparing surgery in laparoscopy, as evidenced by the initial experience with laparoscopic partial nephrectomy, which carries a high risk of complications (13-15). In fact, most cases of laparoscopic partial nephrectomy have shown successful results only in small tumor sizes. Desai et al. (16) reported successful results in suture repair of the pelvicaliceal system with laparoscopy; however, their data was obtained with tumors with a mean size of $3.4 \mathrm{~cm}$ and $<7 \mathrm{~cm}$ maximum size. In our series, the mean tumor size was $>5 \mathrm{~cm}$ when knot tying was performed with the help of expanded polytetrafluoroethylene and Hem-O-Lok ${ }^{\circledR}$. Furthermore, the large tumor (10 $\mathrm{cm}$ in diameter) in our series, which occupied nearly one-third of the kidney, did not result in any acute or delayed complications following successful renal parenchymal repair with the combined method (Figure-2).

Recently, commercially available fibrin tissue sealants and gelatin matrix-thrombin tissue sealants have been used to assist in hemostasis and collecting system closure during open and laparoscopic partial nephrectomy with apparent clinical success $(17,18)$. Despite the growing clinical application of those methods during partial nephrectomy, there exists little information with regard to the in vivo properties for preventing the major complications of partial nephrectomy. In our series, other additional intracorporeal hemostatic agents were not necessary because the tensile strength was sufficient to keep the repaired parenchyma firm without any acute or delayed complications, such as urine leakage or hematoma formation. Expanded polytetrafluoroethylene and Hem-O-Lok ${ }^{\circledR}$ provided sufficient tensile strength extracorporeally, therefore, no adverse reactions due to foreign materials was expected. Thus, our surgical technique could prevent completely two major complications, those are, postoperative hemorrhage and urine leakage. It should be validated from large series. According to recent large series, on the other 
hand, postoperative hemorrhage after LPN and OPN were reported at $4.2 \%$ and $1.6 \%$ of cases respectively. Urine leakage after LPN and OPN were reported at $3.1 \%$ and $2.3 \%$ of cases respectively (19).

The use of expanded polytetrafluoroethylene preserved the remaining renal parenchyma without injury, such as the "cheese-slicing" effect of knot tying. However, the expanded polytetrafluoroethylene sometimes showed insufficient tensile strength for keeping the "fragile" renal parenchyma safe from injury. Therefore, knot tying during OPN with expanded polytetrafluoroethylene only took excessive time for correcting the knots. In our results, the mean cold ischemic time (CIT) of the combined group was longer than the mono-material group, but without a significant difference in time. Based on the mean tumor size, the acceptable mean CIT of the combined group compared with mono-material group could be explained in two ways. First, the combined method needed fewer attempts for needle passing because cinching was obtained with the interrupted suture method, while the mono-material method required at least 2-fold more attempts due to the vertical mattress suture method. Second, the tensile strength was easily obtained with the combined method because Hem-O-Lok ${ }^{\circledR}$ offers parallel tension to the capsular surface, while the monomaterial method delivers upward or downward forces perpendicular to the capsular surface.

In respect of cancer control, partial nephrectomy is comparable to radical nephrectomy. Since 2000, 10-year outcome data after nephron sparing surgery in 107 patients have been reported (12). Specific survival rates of cancer were $88.2 \%$ and $73 \%$ at 5 and 10 , years respectively. Another report also showed no difference between survival rates in patients who underwent radical nephrectomy and nephron sparing surgery. Tumor size and stage were the main factors of outcome in both groups (8).

Similar long-term outcome would be expected in our series, whereas the tumor size could not the primary determinant of outcome.

\section{CONCLUSION}

Nephron-sparing surgery using expanded polytetrafluoroethylene $\left(\right.$ Gore-Tex ${ }^{\circledR}$ ) alone or a
Gore-Tex ${ }^{\circledR}$ and Hem-O-Lok ${ }^{\circledR}$ (Weck ${ }^{\circledR}$ Clip) combination was relatively safe without other additional hemostatic agents, irrespective of the tumor size and location because the tensile strength was sufficient to keep the repaired parenchyma firm. Furthermore, the combined method afforded easier handling and less operation time than the mono-material method. No major complications, recurrence, and impaired renal function occurred with either of the procedures.

\section{CONFLICT OF INTEREST}

None declared.

\section{REFERENCES}

1. Herr HW: A history of partial nephrectomy for renal tumors. J Urol. 2005; 173: 705-8.

2. Uzzo RG, Novick AC: Nephron sparing surgery for renal tumors: indications, techniques and outcomes. J Urol. 2001; 166: 6-18.

3. Zincke H, Ruckle HC: Use of exogenous material to bolster closure of the parenchymal defect following partial nephrectomy. Urology. 1995; 46: 96-8.

4. Orvieto MA, Chien GW, Laven B, Rapp DE, Sokoloff $\mathrm{MH}$, Shalhav AL: Eliminating knot tying during warm ischemia time for laparoscopic partial nephrectomy. J Urol. 2004; 172: 2292-5.

5. Shalhav AL, Orvieto MA, Chien GW, Mikhail AA, Zagaja GP, Zorn KC: Minimizing knot tying during reconstructive laparoscopic urology. Urology. 2006; 68: 508-13.

6. Bhayani S, Figenshau R: The Washington university renorrhaphy for robotic partial nephrectomy: a detailed description of the technique displayed at the 2008 world robotic urologic symposium. J Robotic Surg. 2008; 2: 139-40.

7. Hafez KS, Fergany AF, Novick AC: Nephron sparing surgery for localized renal cell carcinoma: impact of tumor size on patient survival, tumor recurrence and TNM staging. J Urol. 1999; 162: 1930-3.

8. Lerner SE, Hawkins CA, Blute ML, Grabner A, Wollan PC, Eickholt JT, et al.: Disease outcome in patients with low stage renal cell carcinoma treated with nephron sparing or radical surgery. J Urol. 1996; 155: 1868-73.

9. Kim FJ, Rha KH, Hernandez F, Jarrett TW, Pinto PA, Kavoussi LR: Laparoscopic radical versus partial 
nephrectomy: assessment of complications. J Urol. 2003; 170: 408-11.

10. Haber GP, Gill IS: Laparoscopic partial nephrectomy: contemporary technique and outcomes. Eur Urol. 2006; 49: 660-5.

11. Gill IS, Desai MM, Kaouk JH, Meraney AM, Murphy DP, Sung GT, et al.: Laparoscopic partial nephrectomy for renal tumor: duplicating open surgical techniques. J Urol. 2002; 167: 469-7; discussion 475-6.

12. Fergany AF, Hafez KS, Novick AC: Long-term results of nephron sparing surgery for localized renal cell carcinoma: 10-year followup. J Urol. 2000; 163: 442-5.

13. McDougall EM, Elbahnasy AM, Clayman RV: Laparoscopic wedge resection and partial nephrectomy--the Washington University experience and review of the literature. JSLS. 1998; 2: 15-23.

14. Janetschek G, Jeschke K, Peschel R, Strohmeyer D, Henning K, Bartsch G: Laparoscopic surgery for stage T1 renal cell carcinoma: radical nephrectomy and wedge resection. Eur Urol. 2000; 38: 131-8.

\author{
Correspondence address: \\ Dr. Dong Soo Park \\ Bundang CHA General Hospital \\ Pochon CHA University \\ Sungnam, South Korea \\ Fax: + 8231 780-5323 \\ E-mail: dsparkmd@cha.ac.kr
}

\section{EDITORIAL COMMENT}

Nephron sparing surgery (NSS) is currently considered the best alternative in treatment of renal tumors $<$ of $4 \mathrm{~cm}$ and its indication is expanding to selected cases of lesions up to $7 \mathrm{~cm}$ in size, based in the comparable oncological outcomes to the standard radical treatment, and the remarkable benefit of preserving renal function. This has gained more relevance after several studies that demonstrate higher risk of develop chronic renal failure after radical nephrectomy (1) and the direct association between
15. Hoznek A, Salomon L, Antiphon P, Radier C, Hafiani M, Chopin DK, et al.: Partial nephrectomy with retroperitoneal laparoscopy. J Urol. 1999; 162: 1922-6.

16. Desai MM, Gill IS, Kaouk JH, Matin SF, Novick AC: Laparoscopic partial nephrectomy with suture repair of the pelvicaliceal system. Urology. 2003; 61: 99-104.

17. Pruthi RS, Chun J, Richman M: The use of a fibrin tissue sealant during laparoscopic partial nephrectomy. BJU Int. 2004; 93: 813-7.

18. Richter F, Schnorr D, Deger S, Trk I, Roigas J, Wille A, et al.: Improvement of hemostasis in open and laparoscopically performed partial nephrectomy using a gelatin matrix-thrombin tissue sealant (FloSeal). Urology. 2003; 61: 73-7.

19. Gill IS, Kavoussi LR, Lane BR, Blute ML, Babineau D, Colombo JR Jr, et al.: Comparison of 1,800 laparoscopic and open partial nephrectomies for single renal tumors. J Urol. 2007; 178: 41-6.

Accepted after revision:

February 27, 2009

renal insufficiency and cardiovascular morbidity and mortality (2).

In recent years, promoted by the rapid develop of minimally invasive surgery, many innovative advances in NSS have been reported with the aim of facilitating renorrhaphy, reducing warm ischemia time and prevent most frequent complications, such as bleeding or urinary leak. The presented study takes part in this trend and presents a well-documented initial experience using a novel technique for open 
partial nephrectomy with encouraging results, especially in terms of reconstruction quality, that seems to be useful in the management of larger and complex located tumors.

Recent publications by Orvieto (3), Shalhav (4), Canales (5) and our group (6) have previously described laparoscopic renorrhaphy techniques based in the use of clips. The main goal is to simplify the procedure by avoiding intracorporeal knot tying, providing a reliable and reproducible reconstruction. The use of Weck Hem-O-lock ${ }^{\circledR}$ clips on the sutures allows a more even distribution of the tension applied on the renal surface with a consequent better coaptation. Studies developed in our laboratory have shown that the tension that can be applied on the parenchyma by using this technique which is almost 3 times higher than the achieved with traditional knot tying. Maintaining the placed stitches perpendicular to the capsule when tightening aid-avoiding tears. Also, clip based renorraphy can be easily retightened if needed to achieve an optimal hemostasis.

The use of PTFE as a reinforcement layer to the vertical mattress suture line to prevent parenchymal tears is an interesting addition to the open approach made by this group, not previously reported in the literature, sustained on the same principle of even distribution of tension. Its use could gain relevance during the repair of larger defects, when the renal capsule has been damaged or when clips are not available or secure to use. Thus, the implementation of these advances could be the explanation for the optimal hemostasis and collecting system closure, represented in the almost non-existent complications reported in the paper.

The usual limitations of retrospective design and single-surgeon experience are present in this and many other studies. A randomized prospective study comparing this new approach to the traditional partial nephrectomy technique using a knot-tying reconstruction could be a valuable addition to establish differences.
Finally, it is important to remember that despite of living in a minimally invasive surgery era, open partial nephrectomy still maintains a place of excellence in the armamentarium of urologists devoted to NSS, and so, any further improvements to this classical technique will always be welcome.

\section{REFERENCES}

1. Huang WC, Levey AS, Serio AM, Snyder M, Vickers AJ, Raj GV, et al.: Chronic kidney disease after nephrectomy in patients with renal cortical tumours: a retrospective cohort study. Lancet Oncol. 2006; 7: $735-40$.

2. Go AS, Chertow GM, Fan D, McCulloch CE, Hsu $\mathrm{CY}$ : Chronic kidney disease and the risks of death, cardiovascular events, and hospitalization. $\mathrm{N}$ Engl J Med. 2004; 351: 1296-305. Erratum in: N Engl J Med. 2008; 18: 4.

3. Orvieto MA, Chien GW, Laven B, Rapp DE, Sokoloff $\mathrm{MH}$, Shalhav AL: Eliminating knot tying during warm ischemia time for laparoscopic partial nephrectomy. J Urol. 2004; 172: 2292-5.

4. Shalhav AL, Orvieto MA, Chien GW, Mikhail AA, Zagaja GP, Zorn KC: Minimizing knot tying during reconstructive laparoscopic urology. Urology. 2006; 68: 508-13.

5. Canales BK, Lynch AC, Fernandes E, Anderson JK, Ramani AP: Novel technique of knotless hemostatic renal parenchymal suture repair during laparoscopic partial nephrectomy. Urology. 2007; 70: 358-9.

6. Bhayani S, Figenshau R: The Washington university renorrhaphy for robotic partial nephrectomy: a detailed description of the technique displayed at the 2008 world robotic urologic symposium. J Robotic Surg. 2008; 2: 139-40.

Dr. Jose M. Cabello \&
Dr. Sam B. Bhayani
Department of Surgery
Division of Urologic Surgery
Washington University School of Medicine
Saint Louis, Missouri, USA
E-mail: cabelloj@wudosis.wustl.edu

Dr. Jose M. Cabello \& Dr. Sam B. Bhayani Department of Surgery niversity School of Medicine 


\section{EDITORIAL COMMENT}

In patients with a normal contralateral kidney and tumors up to $4 \mathrm{~cm}$ partial nephrectomy (PNE) should nowadays be considered as first-line therapy. PNE is, however, indicated up to a tumor diameter of $7 \mathrm{~cm}$ in selected patients and subject to tumor location. In cases of singularly kidney, there is an imperative indication for nephron sparing surgery. Nowadays, a laparoscopic approach is an alternative in experienced hands $(1,2)$.

Several techniques exist for PNE with various modifications. It starts with the operative access, which depends strongly on the tumor position. Ischemia time is a crucial issue. In anticipated ischemia exceeding more than 30 minutes there is a consensus to use hypothermia via arterial perfusion with cold lactated Ringer`s solution $(3,4)$. Cold ischemia is required in about $15 \%$ of all cases. The rest is done in warm ischemia with occlusion of only the artery(5). The artery is not occluded by clamps when cold perfusion is foreseen in order to avoid intimal lesion. Instead of clamps, the use of tourniquets is easily applicable without additional measurements. When resulting in a bloodless field tumor excision is feasible with good differentiation between normal and tumor tissue minimizing the risk of unrecognized positive surgical margins.

We achieve laparoscopy hemostasis by two layers of running sutures and knot tying supported by restorable clips. The first suture includes the interstitial tissue and the collecting system if injured. The cut edges of the parenchyma are then adapted by a second running suture, which includes the placement of a bolster of hemostatic material under the suture. The suture is again secured by clips, which accelerate tying and avoid the suture cutting through parenchymal tissue also under traction force. As a last step, the surface is sealed by fibrin glue to avoid prolonged oozing. This technique has proved its safety for laparoscopic procedure in respect to intra-/postoperative complications, surgical margins, side effects and urinary leakage (6). Application of fibrin glue instead of suturing has serious advantages: it is easy, quick, and avoids potential tissue damage caused by sutures. This hypothesis was preliminary confirmed by a comparative investigation, which proved a statistically significant reduction of functional parenchyma loss by the use of glue for parenchyma closure (7). On the other hand, it is obvious that glue cannot deal with large tumors and suture-comparable reliability. The predictability of glue safety is limited in the individual case.

A very comprehensive study in a hypertensive pig model showed that bio-glues were efficient to close small lesions, whereas they proved to be unable to deal with reliable closure of large parenchymal defects. Sutures, in contrast, have high reliability to provide sufficient hemostasis. The only disadvantage is the time for suture placement and tying which cannot be neglected in a procedure in which time really matters - in particular, of course, in laparoscopic procedures in which suturing generates a by far higher delay than in open surgery.

In the present study, the authors describe a tissue closure by Gore-Tex ${ }^{\circledR}$ alone (group 1) or in combination with Hem-O-Lok ${ }^{\circledR}$ clips (group 2). The decision to which method has to be applied was made depending on the tumor size, which provided an objective rationale for the decision. All surgeries showed no side effects perioperatively as well as in long term follow up which was extended to remarkable 3.5 years. Length of ischemia time was absolutely justifiable in both groups. According to recent literature the authors fulfill with their type of parenchymal closure in open PNE all criteria of safety and reliability within the range of time, rate of side effects and long term renal function. Based on this rich experience a switch to laparoscopy should be considered in order to provide optimal up to date patient care.

\section{REFERENCES}

1. Albqami N, Janetschek G: Indications and contraindications for the use of laparoscopic surgery for renal cell carcinoma. Nat Clin Pract Urol. 2006; 3: 32-7.

2. Gill IS, Matin SF, Desai MM, Kaouk JH, Steinberg A, Mascha E, et al.: Comparative analysis of laparoscopic versus open partial nephrectomy for renal tumors in 200 patients. J Urol. 2003; 170: 64-8.

3. Janetschek G, Abdelmaksoud A, Bagheri F, Al-Zahrani H, Leeb K, Gschwendtner M: Laparoscopic partial 
nephrectomy in cold ischemia: renal artery perfusion. J Urol. 2004; 171: 68-71.

4. McLoughlin GA, Heal MR, Tyrell IM: An evaluation of techniques used for the production of temporary renal ischaemia. Br J Urol. 1978; 50: 371-5.

5. Janetschek G: Partial nephrectomy for renal cell carcinoma: trust suturing. J Endourol. 2008; 22: 1933-5; discussion 1943.

6. Häcker A, Albadour A, Jauker W, Ziegerhofer J, Albquami $\mathrm{N}$, Jeschke $\mathrm{S}$, et al.: Nephron-sparing surgery for renal tumours: acceleration and facilitation of the laparoscopic technique. Eur Urol. 2007; 51: 358-65.

7. Hidas G, Lupinsky L, Kastin A, Moskovitz B, Groshar D, Nativ O: Functional significance of using tissue adhesive substance in nephron-sparing surgery: assessment by quantitative SPECT of 99m Tc-Dimercaptosuccinic acid scintigraphy. Eur Urol. 2007; 52: 785-9.

\section{Dr. Reinhold Zimmermann} Department of Urology Elisabethinen Hospital University affiliated Hospital Linz, Austria

E-mail: reinhold.zimmermann@elisabethinen.or.at 